\title{
Management of a Large Periapical Lesion Using Laser Assisted Disinfection in Regenerative Endodontic Therapy - A Case Report
}

\author{
Divya Doddamani*, Saraswathi V. Naik, Basappa Nadig, Archana P. Betur
}

Bapuji Dental College and Hospital, Davangere, India

\section{INTRODUCTION}

Traumatic injuries of teeth could be one of the causes for large periapical lesions. The success of endodontic treatment in such large lesion is directly related with elimination of pathogenic microorganisms from root canal and it depends on resolution of all the clinical signs and symptoms with complete periapical tissue repair or regeneration [1].

Regenerative endodontic therapy (RET) in a tooth with apical periodontitis and apical abscess resulted in the regression of clinical signs and symptoms and healing of apical periodontitis. The success of RET in a tooth with large periapical lesion may depend on the eradication of microbes from the root canal system. Uncontrolled infection will hamper repair and regeneration by the release of pro-inflammatory cytokines, such as tumor necrosis factor-alpha, interleukin - 1 alpha are capable of inhibiting stem cell differentiation. SCAP (Stem cells of apical papilla) introduced in the canal space showed an osteogenic differentiation instead of odontogenic differentiation in the presence of bacterial byproducts. Therefore, the intra-radicular infection should be controlled for pulp and peri radicular tissue regeneration and repair [2].

Lasers assisted disinfection methods can always be used effectively along with other traditional disinfection methods. Primary goal of laser in disinfection is to eradicate microorganisms, removal of debris and smear layer which will ensure successful endodontic therapy. Effectiveness of laser assisted disinfection has been documented in treating periapical lesion. Photodynamic therapy was used to disinfect the root canal and platelet-rich fibrin was used to revitalize the pulp. Disinfection with photodynamic therapy combined with platelet-rich fibrin leads to satisfactory root development in 10 months [3]. Efficacy of diode laser has been proved in disinfection of root canals and maturogenesis of immature teeth. Disinfection plays a major role in successful outcome of teeth treated with regenerative endodontics [4]. This case report aims to describe the regenerative endodontic outcome in necrotic young permanent teeth with large periapical lesion when treated with laser assisted disinfection.

\section{Vol No: 05, Issue: 01}

Received Date: November 21, 2021

Published Date: December 01, 2021

\section{*Corresponding Author}

Dr. Divya Doddamani

Department of Pedodontics and Preventive Dentistry, Bapuji Dental College and Hospital, MCC B Block, Davangere, India. Tel: +919739216624

E-mail: divya.anepalla@gmail.com

Citation: Doddamani D, et al. (2021). Management of a Large Periapical Lesion Using Laser Assisted Disinfection in Regenerative Endodontic Therapy A Case Report. Mathews J Dentistry. 5(1):28.

Copyright: Doddamani D, et al. (C) (2021). This is an open-access article distributed under the terms of the Creative Commons Attribution License, which permits unrestricted use, distribution, and reproduction in any medium, provided the original author and source are credited. 


\section{CASE REPORT}

A 11-year-old female reported with chief complaint of pain in the upper front teeth region since 3 weeks. Patient gave a history of trauma 2 years ago. Clinical examination revealed normal soft tissues and tooth 21 negative to electric pulp test. Percussion testing revealed tenderness in tooth 21. CBCT (Cone beam computerized tomography) evaluation showed an open apex periapical radiolucency, thinning of the labial cortex (Figure 1). A diagnosis of Periapical granuloma was made. Clinical procedures for REP were performed as per American Association of Endodontics 2016 protocol for Regenerative Endodontics after obtaining the informed consent from the patient. In the first appointment copious, gentle irrigation was done with $20 \mathrm{ml}$ of $1.5 \%$ Sodium hypochlorite $(\mathrm{NaOCl})$ with side vented closed needle $(20 \mathrm{ml} /$ canal, $5 \mathrm{~min}$ ), followed by disinfection was performed with $810 \mathrm{~nm}$ diode laser (AMD LASERS Picasso Dental Diode Laser) with power $1 \mathrm{~W}, 20 \mathrm{~ms}$ Pulse length and $20 \mathrm{~ms}$ interval duration. The optical fibre tip (200 micron) introduced $1 \mathrm{~mm}$ short of the working length and laser irradiation was performed with the irrigant in the canal for 15s, [5] followed by $17 \%$ Ethylene diamine tetra acetic acid (EDTA) irrigation. Dentin bonding agent was applied to minimize risk of staining. Triple antibiotic paste (TAP) mixture in the ratio of 1:1:1 ciprofloxacin: metronidazole: minocycline to a final concentration of $1-5 \mathrm{mg} / \mathrm{ml}$ was placed as intracanal medicament. Access cavity was sealed and patient was recalled after 4 weeks. Same procedure was repeated. After 4 weeks, in the third appointment, copious, gentle irrigation with $20 \mathrm{ml}$ of $17 \%$ EDTA. Blood clot scaffold was placed inside the root canal by over instrumenting with pre-curved No. $15 \mathrm{~K}$ file (MANI Inc., Japan). Collagen plug (Colla Cote (TM)) was placed over the blood clot. 3-4 mm MTA (MTA Plus) coronal seal was placed. Composite build up done. At 18 months follow up tooth was clinically asymptomatic, CBCT follow up showed blunt end apical closure, significant reduction in the size of the periapical radiolucency, a radioopaque mass indicating the formation of new bone was shown with radiographic density value 660 HU (Hounsfield Unit). Blunt end root closure and intra canal calcification was noted (Figure 2). Radio opaque mass was shown indicating bone formation at the periapical region.
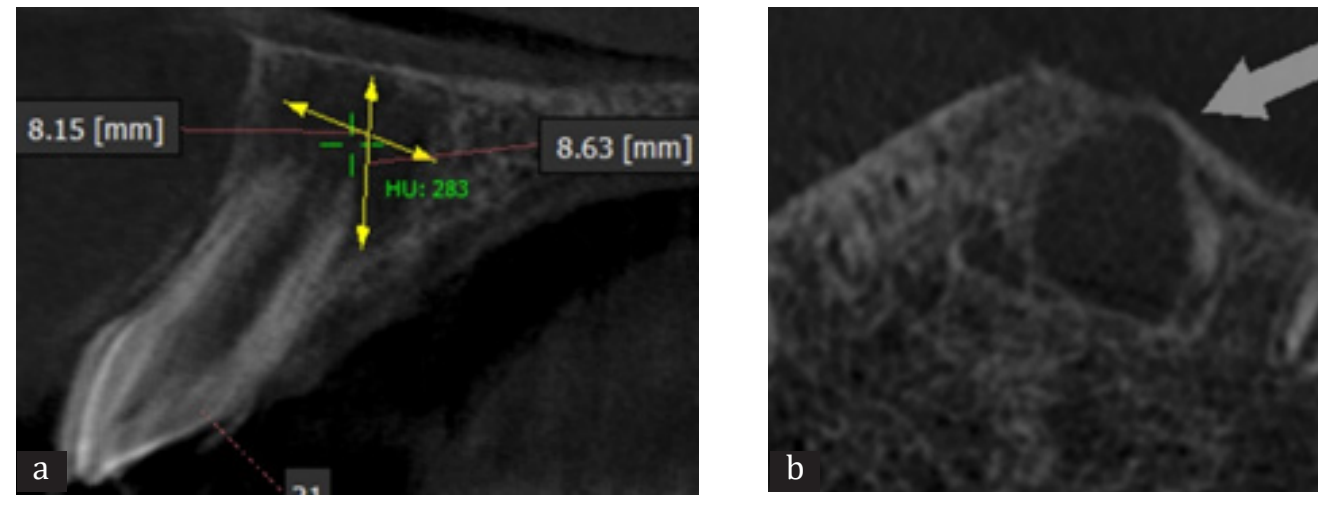

Figure 1: Preoperative CBCT wrt21. a) Sagittal Section shows periapical radiolucency measuring $8.15 \mathrm{X} 8.63 \mathrm{~mm}, 283 \mathrm{HU}$. b) Thinning of the labial cortex at the level $5 \mathrm{~mm}$ above the apex.
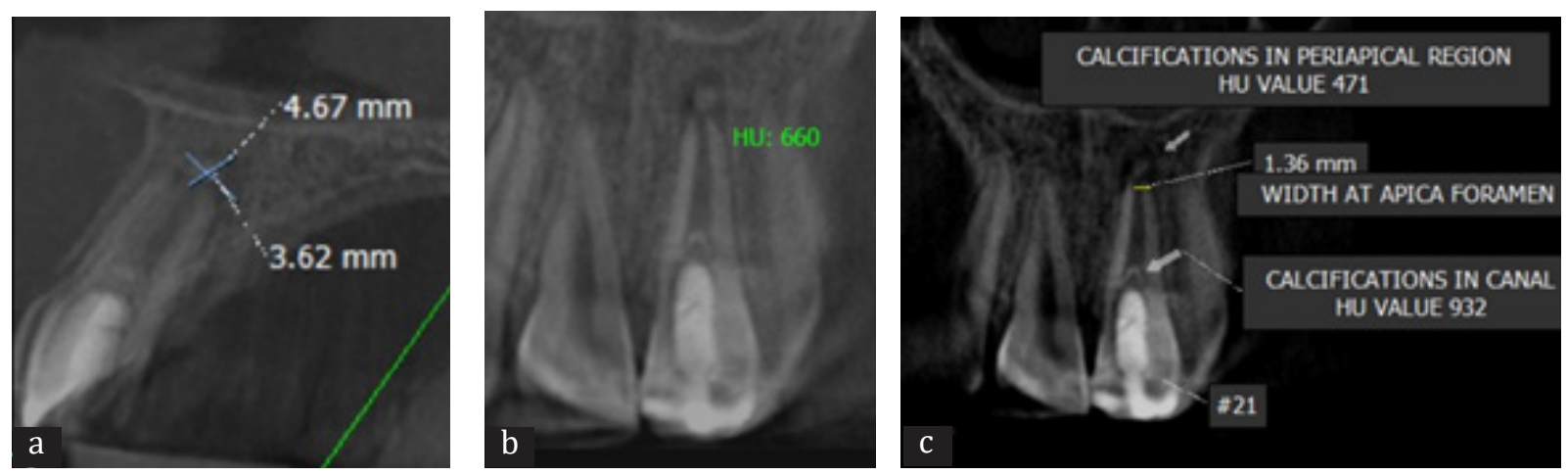

Figure 2: 18 months CBCT Follow up. a) Sagittal section shows reduction in the size of periapical radiolucency measuring $4.67 \times 3.62 \mathrm{~mm}$, Blunt end root closure and intra canal calcification. b) Coronal section shows calcification in the coronal aspect of the root with $932 \mathrm{HU}$ value. c) Coronal section shows radio-opacity indicating bone formation at the periapical region. 


\section{DISCUSSION}

The role of stem cells for cell-based therapy is known since long. SCAP are capable of forming odontoblast-like cells and help in the formation of root dentin. SCAP can survive even after pulp necrosis because of their proximity to the periapical tissue vasculature. Under the influence of Hertwig's epithelial root sheath, SCAP can form dentin when proper disinfection protocols are followed. Cytokines, such as IL 6, found in the inflamed site may increases the stemness of mesenchymal stem cells. Resolution of the apical lesion and regression of clinical signs and symptoms are documented in teeth treated with RET [6].

CBCT being a non-invasive method of diagnosis with high specificity and excellent accuracy, can enhance the chance of a more accurate preoperative diagnosis of periapical lesions. CBCT is recommended for pre-operative evaluation and follow up evaluation of lesions such as granuloma as well as outcomes of RET [7].

The key factor for the successful revascularization of immature teeth is adequate disinfection. The disinfection approach was chemical rather than chemo-mechanical. Therefore, sterile necrotic pulp and blood clot scaffold are essential in providing a lattice for cell growth. The laser activation of irrigating solutions such as EDTA or $\mathrm{NaOCl}$ will enhance the removal of the smear layer and bacterial biofilm. After absorption of laser energy by the solution, there will be formation of vapor bubbles, collapse of the bubbles, acoustic streaming, and finally cavitation. Intracanal irradiation with diode laser had an effect on the bacteria present even beyond the apex [8]. Use of Photodynamic therapy is well documented in the treatment of periapical lesion which will increase the reduction of microbial load in the endodontic space favouring the regression of the periapical lesion. Recently a case report of regenerative endodontics using photoactivated disinfection showed root closure when followed for 10 months follow up [3].

As an intracanal medicament triple antibiotic paste is effective in pulp revascularization. The absence of symptoms and periapical healing was observed when TAP was used as intracanal medicament [9].

Blood clot scaffold is the gold standard for regenerative endodontic therapy in younger population because of its extremely favourable and clinically feasible properties among paediatric patients compared to other scaffold systems like Platelet rich fibrin or platelet rich plasma. Blood clot being cell-homing-based approach, the patient's endogenous cells undertake tissue repair/regeneration. Growth factors present in blood clot scaffold plays an important role in cell differentiation. The growth factors such as plateletderived growth factor, vascular endothelial growth factor, and platelet-derived epithelial growth factor from blood clot promotes regeneration. Majority of type of apical response seen after using blood clot was no significant increase in the root length. Five types of apical responses were observed where intra canal calcification is one type of outcome. Resolution of apical periodontitis and revascularizationassociated intracanal calcification (RAIC) was a finding noted in $62.1 \%$ (calcific barrier and canal obliteration) [10].

MTA induces cell differentiation and mineralization using the mitogen-activated protein kinase pathway of mineralization, focusing on the influx of calcium ions. They also help in the release of TGF-b1 from root canal dentin. Hence MTA can be used as the coronal seal material in regenerative endodontic cases.Other benefit of MTA is because of its high pH after mixing with water, which raises the $\mathrm{pH}$ from 10.2 to 12.5 after 3 Hrs. Therefore, it is less cytotoxic, with good sealing and better marginal adaption compared to glass ionomer cement (GIC). Hard tissue forming cells differentiate and migrate onto the MTA surface, forming a biological seal [11]. Use of collagen matrix for the controlled placement of MTA to a desired and optimal level, with only light pressure placed on the MTA during packing is recommended [12].

18 months follow up showed considerable reduction in the size of the peri radicular radiolucency and formation of bone and blunt end closure of root apex, hard tissue barrier at cervical third and blunt end closure of root apex. This indicates the process of healing and this case has to be followed up further.

\section{CONCLUSION}

This case report documents the efficacy of laser-assisted disinfection with TAP intra canal medicament which showed quantitative outcomes of REP when followed for 18 months with CBCT follow up.

\section{DISCLOSURE OF INTEREST}

The authors declare that they have no conflict of interest.

\section{REFERENCES}

1. Karamifar K, Tondari A, Saghiri MA. (2020). Endodontic Periapical Lesion: An Overview on the Etiology, Diagnosis and Current Treatment Modalities. Eur Endod J. 2:54-67. 
2. Vishwanat L, Duong R, Takimoto K, Phillips L, Espitia CO, et al. (2017). Effect of Bacterial Biofilm on the Osteogenic Differentiation of Stem Cells of Apical Papilla. J Endod. 43(6):916-922.

3. Johns DA, Shivashankar VY, Krishnamma S, Johns M. (2014) Use of photoactivated disinfection and plateletrich fibrin in regenerative Endodontics. J Conserv Dent. 17(5):487-490.

4. El A, Ossama R, Mekkawi E, Abd-El M, Kataia R, Ali $\mathrm{MM}$, et al. Evaluation of the Efficacy of Diode Laser in Maturogenesis of Immature Teeth with Necrotic Pulps: An in Vivo Study "Part One." (2020) Indian J Public Heal Res Dev. 11(3):1387.

5. Naik R, Raviraj G, Yavagal C, Mandroli P. (2017). Diode lasers for pediatric endodontics: State-of-the-art! J Dent Lasers. 11(1):7.

6. Lin LM, Shimizu E, Gibbs JL, Loghin S, Ricucci D. (2014). Histologic and histobacteriologic observations of failed revascularization/revitalization therapy: a case report. J Endod. 40(2):291-295.

7. Meschi N, EzEldeen M, Torres Garcia AE, Jacobs R, Lambrechts PA. (2018). A Retrospective Case Series in Regenerative Endodontics: Trend Analysis Based on Clinical Evaluation and 2- and 3-dimensional Radiology. J Endod. 44(10):1517-1525.
8. Hmud R, Kahler WA, George R, Walsh LJ. (2010). Cavitational effects in aqueous endodontic irrigants generated by near-infrared lasers. J Endod. 36(2):275278.

9. do Couto AM, Espaladori MC, Leite APP, Martins CC, de Aguiar MCF, et al. (2019). A Systematic Review of Pulp Revascularization Using a Triple Antibiotic Paste. Pediatr Dent. 41(5):341-353.

10. Song M, Cao Y, Shin SJ, Shon WJ, Chugal N, Kim RH, Kim E, Kang MK. (2017). Revascularization-associated Intracanal Calcification: Assessment of Prevalence and Contributing Factors. J Endod. 43(12):2025-2033.

11. Wattanapakkavong K, Srisuwan T. (2019). Release of Transforming Growth Factor Beta 1 from Human Tooth Dentin after Application of Either ProRoot MTA or Biodentine as a Coronal Barrier. J Endod. 45(6):701-705.

12. Petrino JA, Boda KK, Shambarger S, Bowles WR, McClanahan SB. (2010). Challenges in regenerative endodontics: a case series. J Endod. 6(3):536-541. 